\title{
Resultater etter assistert befruktning i en offentlig fertilitetsklinikk
}

\author{
Sammendrag \\ Bakgrunn. Assistert befruktning er \\ tradisjonelt ansett som virkningsfull \\ når den gir høy andel graviditeter per \\ behandlingsfors $ø$ k. For pasientene er \\ det mer interessant å vite hvor stor \\ sannsynligheten er for å få barn i løpet \\ av et helt behandlingsløp med assistert \\ befruktning.
}

Materiale og metode. Studien er en retrospektiv pasientserie som inkluderte alle pasienter som hadde dato for menstruasjon før første behandlingsfors $ø$ k hos Fertilitetsklinikken Sør ved Sykehuset Telemark mellom 1.1. 2006 og 1.7. 2007. Pasientene ble fulgt i tre år.

Resultater. 546 pasienter ble inkludert. I løpet av oppfølgingsperioden fikk $347(63,6 \%)$ av pasientene barn ved assistert befruktning. Blant de 199 resterende pasientene var det 70 som avsluttet sitt behandlingsløp fordi de hadde fullført de tre behandlingsforsøkene som dekkes av det offentlige. 37 pasienter fikk barn utenom assistert befruktning.

Fortolkning. Assistert befruktning ved en offentlig fertilitetsklinikk i Norge er like virkningsfullt som i våre naboland. De siste 18 år har virkningsgraden av assistert befruktning økt med omkring $50 \%$.

\author{
Hans Ivar Hanevik \\ hhai@sthf.no \\ Jarl A. Kahn \\ Anette Bergh \\ Ellen Eriksen \\ Unn Mette Friberg \\ Caroline Vegheim Haraldsen \\ Trine Gullhaug Nilsen \\ Astrid Helene Sydtveit \\ Paula Rode \\ Fertilitetsklinikken Sør \\ Sykehuset Telemark \\ Porsgrunn
}

Assistert befruktning hjelper infertile pasienter til å få barn. Tradisjonelt er assistert befruktning ansett som virkningsfull når den gir høy andel graviditeter per startet behandlingsforsøk med in vitro-fertilisering/intracytoplasmatisk spermieinjeksjon (IVF/ICSI). Denne vurderingen av virkningsgrad har flere svakheter (1). Et hovedproblem er at graviditeter per behandlingsforsøk ikke sier noe om hvor lenge graviditeten vedvarer - pasientene ønsker seg barn, ikke spontanaborter. Pasientene ønsker dessuten å vite hvor stor sannsynligheten er for å få barn i løpet av et helt behandlingsløp med assistert befruktning, og hvor mange behandlingsfors $ø \mathrm{k}$ uten barn det er verd å gjennomføre før man gir seg. Slik informasjon er i tillegg nyttig for lovgivere som skal beslutte hvor mye av kostnadene ved assistert befruktning i Norge som skal finansieres over skatteseddelen.

Klinikker for assistert befruktning i Norge utfører forskjellige behandlingstyper underlagt bioteknologiloven (2). Pasienter med uforklarlig infertilitet tilbys ofte inseminering med mannens sæd. Det er ikke satt noen øvre begrensning for hvor mange behandlingsforsøk med inseminering pasienter kan få i det offentlige helsevesenet. Hos pasienter som trenger befruktning utenfor kroppen for å bli gravide tilbys in vitro-fertilisering/intracytoplasmatisk spermieinjeksjon. Et slikt behandlingsforsøk består i grove trekk av kontrollert ovarial hyperstimulering, uttak av oocytter, befruktning av disse i laboratoriet, tilbakeføring av embryo(er), nedfrysing av overskuddsembryo(er), opptining og tilbakesetting av fryst(e) embryo(er). I det offentlige helsevesenet i Norge er antall slike behandlingsforsøk, dersom de ikke blir avbrutt eller gir barn, begrenset til tre per pasient.

Ved å følge en gruppe pasienter i et helt behandlingsløp med assistert befruktning får man et mer helhetlig og informativt bilde av behandlingens virkningsgrad. Det foreligger slike pasientserier av relativt ny dato fra Sverige (3), Danmark (4), og Nederland (5). Funnene i disse studiene er ikke direkte overførbare til norske forhold på grunn av variasjoner mellom landene hva gjelder finansiering, lovgivning og til en viss grad behandlingstradisjoner. Den eneste publiserte norske pasientserien der man har vurdert virkningsgraden av assistert befruktning er fra 1993 (6). Den er ikke lenger representativ på grunn av utviklingen i fagfeltet.

Her presenteres en retrospektiv pasientserie fra Fertilitetsklinikken Sør ved Sykehuset Telemark. Hovedmålet med studien var å finne sannsynligheten for å få barn etter assistert befruktning ved en offentlig fertilitetsklinikk i Norge.

\section{Materiale og metode}

Pasientene som ble inkludert i denne retrospektive pasientserien var til assistert befruktning hos Fertilitetsklinikken Sør med en eller begge av følgende to behandlingstyper: «fallopian tube sperm perfusion» (en form for inseminering) (7); in vitro-fertilisering/intracytoplasmatisk spermieinjeksjon inkludert intracytoplasmatisk spermieinjeksjonetter kirurgisk uthenting av spermier fra testikkelen $(8$, 9). Alle pasientene som ble inkludert i pasientserien hadde dato for menstruasjon før første behandlingsfors $ø$ hos Fertilitetsklinikken Sør i perioden 1.1.2006-1.7. 2007. Pasientene ble fulgt til samme dato tre år senere, senest 1.7. 2010. Pasientene innfridde kravene som stilles i bioteknologiloven for behandling med assistert befruktning (2).

Pasientene forlot pasientserien da de fikk

\section{Hovedbudskap}

- Innen tre år etter startet assistert befruktning fikk 70,3\% av pasientene barn

- $29,7 \%$ av fødslene kom etter tilbakeføring av tint(e) embryo(er)

- Den kumulative andelen av pasienter som fødte økte for hvert behandlingsforsøk

- Innen tre år hadde 98,7\% av pasientene enten fått barn eller forlatt behandlingsløpet 
Tabell 1 Resultater etter assistert befruktning for 546 pasienter fulgt i tre år sortert etter de ulike behandlingstyper som tilbys ved Fertilitetsklinikken $\mathrm{S} \varnothing \mathrm{r}$

\begin{tabular}{|c|c|c|c|c|c|c|c|}
\hline & $\begin{array}{l}\text { Pasienter } \\
\text { med behand- } \\
\text { lingsfors } ø \text { k }\end{array}$ & $\begin{array}{l}\text { Påbegynte } \\
\text { behand- } \\
\text { lingsforsøk }\end{array}$ & $\begin{array}{l}\text { Avbrutte behand- } \\
\text { lingsfors } ø \text { k før } \\
\text { tilbakeføring } \\
\text { av embryoler) } \\
\text { (\% av påbegynte } \\
\text { behandlingsfors } \varnothing \text { ) }\end{array}$ & $\begin{array}{c}\text { Kliniske } \\
\text { graviditeter }{ }^{1} \\
\text { (\% av påbegynte } \\
\text { behandlings- } \\
\text { forsøk) }\end{array}$ & $\begin{array}{c}\text { Spontanaborter } \\
\text { inkludert ekstra- } \\
\text { uterine gravidite- } \\
\text { ter ( } \% \text { av kliniske } \\
\text { graviditeter) }\end{array}$ & $\begin{array}{c}\text { Fødsler } \\
\text { (\% av påbegynte } \\
\text { behandlings- } \\
\text { fors } \varnothing \mathrm{k})\end{array}$ & $\begin{array}{c}\text { Tilbakeføringer } \\
\text { av ett embryo } \\
\text { (\% av tilbake- } \\
\text { føringer) }\end{array}$ \\
\hline $\begin{array}{l}\text { «Fallopian tube } \\
\text { sperm perfusion» }\end{array}$ & 47 & 69 & $11(15,9)$ & $8(11,6)$ & 0 & $8(11,6)$ & Ikke aktuelt \\
\hline In vitro-fertilisering & 254 & 376 & $51(13,6)$ & $118(31,4)$ & $19(16,1)$ & $99(26,3)$ & $163(50,2)$ \\
\hline $\begin{array}{l}\text { Intracytoplasmatisk } \\
\text { spermieinjeksjon }\end{array}$ & 334 & 580 & $76(13,1)$ & $163(28,1)$ & $26(16,0)$ & $137(23,6)$ & $207(41,1)$ \\
\hline $\begin{array}{l}\text { Tilbakeføring av } \\
\text { tintle) embryoler) }\end{array}$ & 266 & 616 & $124(20,1)$ & $130(21,1)$ & $27(20,8)$ & $103(16,7)$ & $138(28,0)$ \\
\hline Totalt & Ikke aktuelt & 1641 & $262(16,0)$ & $419(25,5)$ & $72(17,2)$ & $347(21,1)$ & Ikke aktuelt \\
\hline
\end{tabular}

barn. I denne sammenheng skjer det ved fødsel etter 22 uker og 0 dagers svangerskapsvarighet, i henhold til Medisinsk fødselsregisterforskrift (10). Svangerskapsvarigheten ble beregnet ut fra Naegles regel med dag for injeksjon av humant choriongonadotropin satt som dag 12 i en tenkt menstruasjonssyklus.

Tiden fra første behandlingsforsøk til det behandlingsforsøket som gjorde at pasienten fikk barn, er beregnet ut fra dato for siste menstruasjon før behandlingsforsøket startet. Det ble ikke tatt hensyn til dem som ikke fikk barn i analysene av denne tiden.

Dataene som danner grunnlaget for studien samles inn som rutine ved Fertilitetsklinikken Sør til bruk i klinisk arbeid og kvalitetssikring. Det ble derfor ikke søkt om godkjenning til prosjektet fra Regional komité for medisinsk og helsefaglig forskningsetikk. Studien ble godkjent av personvernombudet for forskning.

\section{Resultater}

Det var 546 pasienter i serien. Ved inklusjon hadde pasientene gjennomsnittlig alder 32,2 år (95 \% konfidensintervall (KI) 31,9-32,6, spredning 21,8-40,0), gjennomsnittlig vekt $69,7 \mathrm{~kg}$ (95\% KI 68,6-70,9, spredning 41-130), gjennomsnittlig kroppsmasseindeks (BMI) 24,6 kg/m² (95\% KI 24,3-25,0, spredning 16,2-42,5), gjennomsnittlig varighet av infertiliteten 4,4 år $(95 \% \mathrm{KI}$ $4.3-4,6$, spredning $0,8-19,2$ ). Av de 110 pasientene $(20,1 \%$ av 546$)$ som hadde født barn ved inklusjon hadde 85 (77,3\% av 110$)$ født en gang. Hovedårsaken til fertilitetsbehandlingen var: nedsatt sædkvalitet hos partner hos 230 pasienter $(42,1 \%)$; tubefaktor hos 131 pasienter $(24,0 \%)$; uforklarlig infertilitet hos 77 pasienter (14,1\%); ovulasjonssvikt (inkludert polycystisk ovariesyndrom) hos 62 pasienter $(11,3 \%)$; endometriose hos 41 pasienter $(7,5 \%)$; uterine og andre spesifikke årsaker hos fem pasienter $(0,9 \%)$. Det forelå ikke data om hvorvidt pasientene hadde vært til assistert befruktning ved andre klinikker tidligere.

Tabell 1 viser resultatene av assistert befruktning etter behandlingstype. 45 (8,2\%) av pasientene i serien hadde «fallopian tube sperm perfusion» som sin første behandlingstype ved Fertilitetsklinikken Sør. Av de 531 pasientene som hadde behandlings- forsøk med in vitro-fertilisering/intracytoplasmatisk spermieinjeksjon i løpet av oppfølgingstiden hadde 30 (5,6\% av 531) tidligere hatt behandlingsforsøk med «fallopian tube sperm perfusion» ved Fertilitetsklinikken Sør.

Tabell 2 viser resultatene etter in vitrofertilisering/intracytoplasmatisk spermieinjeksjon inkludert tilbakeføring av tint(e) embryo(er). Hver kolonne representerer et startet behandlingsforsøk med denne metoden. Noen behandlingsforsøk måtte avbrytes, for eksempel på grunn av mangel på egnet/egnede embryo(er) for tilbakeføring. Et avbrutt behandlingsfors $ø k$ gir aldri graviditet og teller ikke som et av de tre behandlingsforsøkene i det offentlige helsevesenet. Dog teller avbrudd som et behandlingsforsøk i rekken i tabell 2. På grunn av dette er noen pasienter registrert med opptil seks behandlingsforsøk med in vitro-fertilisering/ intracytoplasmatisk spermieinjeksjon.

199 pasienter forlot pasientserien uten å ha fått barn ved assistert befruktning. Årsakene til dette er vist i tabell 3. Av de 70 pasientene som forlot pasientserien fordi de hadde fullført sine tre behandlingsforsøk i

Tabell 2 Resultater etter behandlingsfors øk med in vitro-fertilisering/intracytoplasmatisk spermieinjeksjon inkludert tilbakeføring av tint(e) embryo(er) i løpet av tre år

\begin{tabular}{|c|c|c|c|c|c|c|c|}
\hline \multicolumn{8}{|c|}{ Behandlingsforsøk i rekken } \\
\hline Resultat & 1 & 2 & 3 & 4 & 5 & 6 & Totalt \\
\hline Pasienter som startet behandlingsfors $\varnothing$ ket & 531 & 259 & 128 & 32 & 5 & 1 & Ikke aktuelt \\
\hline $\begin{array}{l}\text { Antall avbrutte behandlingsfors } \varnothing \mathrm{k} \\
\text { (\% av startet aktuelt behandlingsfors } \varnothing \mathrm{k} \text { ) }\end{array}$ & $132(24,9)$ & $60(23,1)$ & $44(34,4)$ & $12(37,5)$ & $2(40,0)$ & $1(100,0)$ & 251 \\
\hline $\begin{array}{l}\text { Pasienter som ble klinisk gravide } \\
\text { (\% av startet aktuelt behandlingsfors } \varnothing \text { ) }\end{array}$ & $262(49,3)$ & $98(37,8)$ & $44(34,4)$ & $6(18,8)$ & $1(20,0)$ & $0(0)$ & 411 \\
\hline $\begin{array}{l}\text { Pasienter som fødte } \\
\text { (\% av startet aktuelt behandlingsfors } \varnothing \mathrm{k})\end{array}$ & $222(41,8)$ & $78(30,1)$ & $34(26,6)$ & $5(15,6)$ & $0(0)$ & $0(0)$ & 339 \\
\hline Kumulativ andel fødsler per 531 pasienter (\%) & 41,8 & 56,5 & 62,9 & 63,8 & 63,8 & 63,8 & 63,8 \\
\hline $\begin{array}{l}\text { Pasienter som gir seg etter behandlingsfors } ø \text { ke } \\
\text { uten å ha fått barn ved assistert befruktning } \\
\text { (kumulativ andel i \%) }\end{array}$ & $50(9,4)$ & $53(19,4)$ & $62(31,1)$ & $22(35,2)$ & $4(36,0)$ & $1(36,2)$ & 192 \\
\hline
\end{tabular}


det offentlige helsevesenet, kom 24 (34,3 \%) tilbake til Fertilitetsklinikken Sør for til sammen 36 egenbetalte behandlingsforsøk innen oppfølgingstiden. Disse 36 behandlingsforsøkene ga sju fødsler. Andelen fødsler etter de egenbetalte forsøkene er dermed $29,2 \%$ per pasient, og 19,4\% per behandlingsforsøk.

Median tid fra første behandlingsforsøk ved Fertilitetsklinikken Sør til det behandlingsforsøket som gjorde at pasienten fikk barn var 2,8 måneder. Antall måneder mellom første behandlingsforsøk og det behandlingsforsøket som ga barn er vist i figur 1 .

Av de 347 fødslene i pasientserien var 306 enkeltfødsler og $41(11,8 \%)$ tvillingfødsler. Utover dette er det ikke gjort analyser angående svangerskapsvarighet, fødselsforløp eller barnas helse.

\section{Diskusjon}

Tre år etter sitt første behandlingsforsøk hos Fertilitetsklinikken Sør hadde 63,6\% av de 546 pasientene i serien vært til et behandlingsforsøk med assistert befruktning som ga barn. Dette er på nivå med våre naboland. Den mest omfattende studien ble gjort $\mathrm{i}$ Danmark, der 62,8\% av en serie på 1338 infertile pasienter fikk barn ved assistert befruktning i løpet av fem års oppfølgingstid (4). En studie fra Nederland med varierende oppfølgingstid viste en kumulativ fødselsandel på 59,1\% (5). En noe eldre svensk studie rapporterte en kumulativ fødselsandel på 55,5\% (3). Det er, som forventet, en betydelig økning i virkningsgraden av assistert befruktning sammenliknet med den forrige norske undersøkelsen (6). Den rapporterte at $44 \%$ fikk barn, og økningen i virkningsgrad er dermed omkring $50 \%$ på 18 år.

\section{De som får barn}

Hovedandelen av de 347 fødslene kom som følge av tilbakeføring av fersk(e) embryo(er) etter behandlingsfors $ø$ k med in vitro-fertilisering/intracytoplasmatisk spermieinjeksjon (236 fødsler, 68,0 \%). I tillegg kom 103 fødsler $(29,7 \%)$ etter tilbakeføring av tint(e) embryo(er). Dette illustrerer betydningen av at fertilitetsklinikker har et godt fungerende program for frysing og tining av overtallig(e) embryo(er) etter behandlingsforsøk med denne metoden. Åtte fødsler $(2,3 \%)$ etter «fallopian tube sperm perfusion» indikerer at denne behandlingstypen har sin plass $i$ assistert befruktning. Pasienter som på denne måten blir gravide har mindre bivirkninger og mindre teknisk inngripen i befruktningen enn ved in vitro-fertilisering/intracytoplasmatisk spermieinjeksjon.

Tabell 2 viser at sannsynligheten for å lykkes synker ettersom antallet behandlingsforsøk med in vitro-fertilisering/intracytoplasmatisk spermieinjeksjon uten barn stiger. Dette reflekterer den kliniske virkelighet, nemlig at noen pasienter er lette å hjelpe, mens andre har et vanskeligere forløp. I denne pasientserien foreligger et mar-

\begin{tabular}{|c|c|c|}
\hline Årsak & Antall & $\begin{array}{c}\text { Andel av dem } \\
\text { som forlot } \\
\text { behandlingsløpet } \\
(\%)\end{array}$ \\
\hline Fullført sine tre behandlingsfors $ø$ i det offentlige helsevesen & 70 & 35,2 \\
\hline Graviditet som ga barn utenom assistert befruktning & 37 & 18,6 \\
\hline Psykisk sliten av behandlingsfors $ø$ kene & 25 & 12,6 \\
\hline $\begin{array}{l}\text { Medisinsk årsak, for eksempel lav ovarial respons på } \\
\text { behandlingsforsøk }\end{array}$ & 16 & 8,0 \\
\hline Samlivsbrudd & 11 & 5,5 \\
\hline Overgang til annen offentlig klinikk for assistert befruktning & 8 & 4,0 \\
\hline Kroppsmasseindeks over ca. 35 kg/m² & 8 & 4,0 \\
\hline $\begin{array}{l}\text { Pause i behandlingsløpet, har offentlig finansierte } \\
\text { behandlingsfors } \varnothing \text { tilgode }\end{array}$ & 7 & 3,5 \\
\hline Ønsker adopsjon/fosterbarn & 5 & 2,5 \\
\hline Alder over ca. 41 år & 5 & 2,5 \\
\hline Synes de har nok barn & 2 & 1,0 \\
\hline$\emptyset$ konomi & 1 & 0,5 \\
\hline Misfornøyd med Fertilitetsklinikken Sør & 1 & 0,5 \\
\hline Ingen informasjon tilgjengelig & 3 & 1,5 \\
\hline Totalt & 199 & 100 \\
\hline
\end{tabular}

kert fall i sannsynligheten for å få barn per behandlingsforsøk etter behandlingsforsøk 3. Pasientene med fire behandlingsforsøk har minst ett avbrutt behandlingsforsøk bak seg. Ingen av pasientene med fem eller flere behandlingsforsøk fikk barn. Disse pasientene har flere avbrutte behandlingsforsøk bak seg. Fallet i sannsynlighet for å få barn betyr ikke nødvendigvis at man bør avslutte behandlingsløpet etter tre behandlingsforsøk. For det første har pasientene som startet behandlingsforsøk 4, sannsynligvis vanskeligere for å få barn i utgangspunktet enn de som startet behandlingsforsøk 1. Deres avbrutte behandlingsforsøk taler for dette. For det andre har mange pasienter forlatt behandlingsløpet uten å få barn ved assistert befruktning innen behandlingsforsøk 4 . Noen av disse har, relativt sett, lett for å få barn og forlater behandlingsløpet av andre årsaker, for eksempel graviditet utenom assistert befruktning. De som velger å gi seg før fullgått behandlingsløp påvirker andelen som får barn ved behandlingsfors $ø \mathrm{k} 4 \mathrm{i}$ negativ retning. Den tredje, og kanskje mest tungtveiende, årsaken for å si at det er hensiktsmessig for pasienter å fortsette sitt behandlingsløp etter behandlingsforsøk 3 , er resultatene fra de egenbetalte behandlingsforsøkene ved Fertilitetsklinikken Sør. Andelen fødsler på $19,4 \%$ per startet behandlingsforsøk for denne gruppen er en god virkningsgrad av assistert befruktning når man tar argumentene over med i betraktningen. En større pasientserie fra Australia viste at antall fødsler fortsatte å øke med økende antall behandlingsforsøk (11).

Median tid fra første behandlingsforsøk til det behandlingsforsøket som ga barn var 2,8 måneder. Figur 1 viser at tidsfordelingen har en lang hale mot høyre, og at medianen domineres av alle pasientene som lykkes på sitt første behandlingsforsøk. Dette er viktig å understreke slik at pasientene er klar over at assistert befruktning kan pågå over flere år før man til slutt lykkes. Denne pasientserien var for liten til å karakterisere pasientene som ikke ble gravide til tross for mange behandlingsforsøk. En studie viste at alder og ovarial respons ved behandlingsforsøk med in vitro-fertilisering/intracytoplasmatisk spermieinjeksjon var faktorer som påvirket dette (12).

Andelen tvillingfødsler på $11,8 \%$ er fortsatt høy og bør senkes. Tabell 1 viser at Fertilitetsklinikken Sør særlig ved tilbakeføring av tint(e) embryo(er) i større grad kan tilbakeføre kun ett embryo. Dog er andelen tvillingfødsler ikke større ved tilbakeføring av tint(e) enn ved tilbakeføring av ferskt/ferske embryo(er) (data ikke vist). Denne studien hadde ikke data angående helsen til barna som ble født, svangerskapsvarigheten eller fødselsforløpet. Dette er beskrevet i andre studier (13).

\section{De som gir seg}

I løpet av oppfølgingstiden på tre år har 199 $(36,4 \%)$ av de 546 pasientene som inngikk i pasientserien, ikke vært til behandlingsforsøk som ga barn. Årsakene til at pasientene forlot sitt behandlingsløp ved Fertilitetsklinikken Sør er vist i tabell 3, og er omtrent tilsvarende som i en svensk studie (14). Frafallet av 199 pasienter betyr at denne studien underestimerer det fulle potensialet i moderne assistert 
befruktning som vil være høyere dersom færre pasienter forlater behandlingsløpet (4). Det er også verdt å merke seg at oppfølgingen av pasientene i pasientserien slutter når de får barn. Vi kjenner til at flere av pasientene har fått barn nummer 2 etter assistert befruktning etter at de forlot pasientserien.

Den hyppigste grunnen (70 pasienter, $35,2 \%$ av 199) er at pasienten hadde brukt opp sine tre behandlingsforsøk i det offentlige. Om disse fortsatte assistert befruktning ved private klinikker, vites ikke utover det som er beskrevet over for egenbetalte forsøk ved Fertilitetsklinikken Sør.

Til sammen 25 pasienter (12,6\% av 199) valgte å avbryte behandlingsløpet fordi de var psykisk slitne. Dette understreker at assistert befruktning er krevende for pasienten, og at virkningsgrad ikke er det eneste kriteriet på kvalitet $\mathrm{i}$ en medisinsk behandling. Det er usikkert om reduksjon av behandlingsrelatert psykisk stress gjør at flere kan få barn ved assistert befruktning (14).

Pasientene ved Fertilitetsklinikken Sør oppfordres til å prøve å få barn ved samleie utenom behandlingsforsøkene ved klinikken. Dette førte til at 37 av pasientene i serien $(18,6 \%$ av 199) fikk barn utenom assistert befruktning. Om disse 37 fødslene legges til de 347 fødslene ved assistert befruktning, blir andelen av pasientene i pasientserien som i løpet av oppfølgingstiden har oppnådd graviditet som gir barn 70,3\%. Det er usikkert om disse 37 ville ha fått barn uten å være $i$ et behandlingsløp for assistert befruktning.
For eksempel har noen av dem økt sannsynligheten for å få barn utenom assistert befruktning fordi behandlingsforsøkene har etablert en regelmessig menstruasjonssyklus. En del av de 37 kom tilbake for assistert befruktning da de fikk vansker med å få barn nummer 2, men var da ute av pasientserien.

Det var kun sju pasienter $(1,3 \%$ av 546$)$ som i løpet av oppfølgingstiden har offentlige behandlingsforsøk til gode og ikke har gitt seg. Det viser at oppfølgingstiden på tre år omfattet bortimot all assistert befruktning pasientene i serien fikk i det offentlige helsevesenet før de fikk barn.

To pasienter (1,0\% av 199) ga seg fordi de syns de hadde nok barn. Dette er par som har barn fra tidligere forhold, men ingen felles barn. Pasientserien er for liten til å bedømme om par med en slik bakgrunn er mindre motivert for et behandlingsløp med assistert befruktning.

\section{$\emptyset k t$ kvalitet}

Klinikker for assistert befruktning i Norge sender inn årlige rapporter til Helsedirektoratet. Der rapporteres de tradisjonelle mål på virkningsgrad, som graviditet per behandlingsforsøk. Fertilitetsklinikken Sør ble sertifisert etter kvalitetsstandarden ISO 9001: 2008 våren 2011. I forbindelse med dette analyseres resultatene for pasientserier ved Fertilitetsklinikken Sør hvert halvår. Vi mener at analyse av pasientserier, som her, gir et mer helhetlig bilde av behandlingen pasientene ved Fertilitetsklinikken Sør får og resul- tatene av den, sammenliknet med rapporteringen til Helsedirektoratet. Vi mener også at rapportering av pasientserier fra alle landets klinikker for assistert befruktning til et sentralt helseregister designet for dette vil bidra til å bedre kvaliteten på den medisinske behandlingen ufrivillig barnløse får i Norge. Et slikt register vil også sannsynligvis forenkle beregningen av de lavere kostnadene assistert befruktning i det offentlige helsevesenet har i forhold til andre tiltak som kan iverksettes for å øke antall barnefødsler (15). Per i dag mangler et slikt register, til tross for at Norsk forening for assistert befruktning lenge har arbeidet for å få det etablert.

En svakhet ved denne studien er nettopp at den kun har pasienter fra en enkelt fertilitetsklinikk. Dog er det en styrke ved studien at det kun er tre pasienter uten opplysninger om hvorfor de forlot behandlingsløpet og at kun sju av pasientene i serien ennå ikke har fullført sitt behandlingsløp.

\section{Konklusjon}

Studien viser at sannsynligheten for å få barn ved assistert befruktning hos Fertilitetsklinikken Sør var 63,6\% for en pasientserie på 546 pasienter som ble fulgt i tre år. I tillegg fikk $6,7 \%$ av pasientene i serien barn $\mathrm{i}$ oppfølgingstiden utenom assistert befruktning.

Prosjektet har mottatt finansiering fra Sykehuset Telemark.

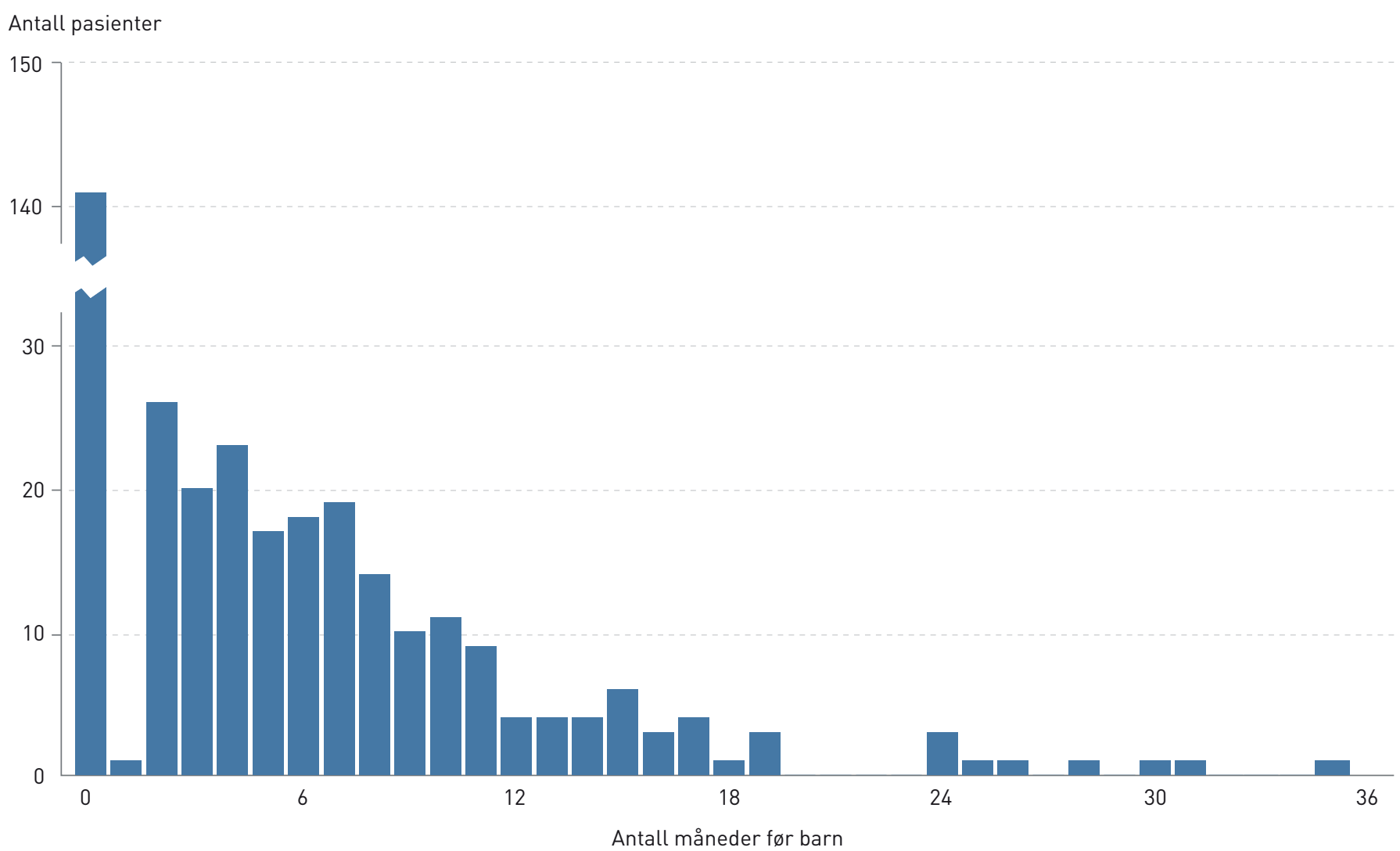

Figur 1 Tiden 347 pasienter brukte på å få barn med assistert befruktning angitt som måneder mellom første behandlingsforsøk og det behandlingsforsøket som ga barn 


\section{Hans Ivar Hanevik (f. 1978)}

er lege i spesialisering og ph.d.-stipendiat ved Fertilitetsklinikken Sør, Sykehuset Telemark HF.

Forfatter har fylt ut ICMJE-skjemaet og oppgir ingen interessekonflikter.

\section{Jarl Arne Kahn (f. 1943)}

er dr.med., spesialist i fødselshjelp og kvinnesykdommer. Forfatteren har arbeidet med assistert befruktning i 30 år, og ledet teamet i Trondheim som førte til det første barnet $ø \varnothing d t$ etter in vitro-fertilisering i Norge. Han er medisinsk ansvarlig for Fertilitetsklinikken Sør. Forfatter har fylt ut ICMJE-skjemaet og oppgir ingen interessekonflikter.

\section{Anette Bergh (f. 1974]}

er cand.scient., «senior clinical embryologist» og senioringeniør. Hun er laboratorieansvarlig ved Fertilitetsklinikken Sør.

Forfatter har fylt ut ICMJE-skjemaet og oppgir ingen interessekonflikter.

\section{Ellen Eriksen (f. 1964)}

er sykepleier ved Fertilitetsklinikken Sør. Forfatter har fylt ut ICMJE-skjemaet og oppgir ingen interessekonflikter.

\section{Unn Mette Friberg (f. 1960)}

er spesialist i fødselshjelp og kvinnesykdommer og er overlege ved Fertilitetsklinikken Sør. Forfatter har fylt ut ICMJE-skjemaet og oppgir ingen interessekonflikter.

\section{Caroline Vegheim Haraldsen (f. 1969)}

er sykepleier ved Fertilitetsklinikken Sør. Forfatter har fylt ut ICMJE-skjemaet og oppgir ingen interessekonflikter.

\section{Trine Gullhaug Nilsen (f. 1967)}

er sekretær ved Fertilitetsklinikken Sør.

Forfatter har fylt ut ICMJE-skjemaet og oppgir ingen interessekonflikter.

\section{Astrid Helene Sydtveit (f. 1983)}

er bioingeniør ved Fertilitetsklinikken Sør Forfatter har fylt ut ICMJE-skjemaet og oppgir ingen interessekonflikter.

\section{Paula Rode (f. 1955)}

er sykepleier og seksjonsleder ved Fertilitetsklinikken Sør.

Forfatter har fylt ut ICMJE-skjemaet og oppgir ingen interessekonflikter.

\section{Litteratur}

1. Heijnen EM, Macklon NS, Fauser BC. What is the most relevant standard of success in assisted reproduction? The next step to improving outcomes of IVF: consider the whole treatment. Hum Reprod 2004; 19: 1936-8.

2. Lov om humanmedisinsk bruk av bioteknologi m.m. (bioteknologiloven). LOV-2003-12-05 nr 100 www.lovdata.no/all/hl-20031205-100.html.

3. Olivius $\mathrm{K}$, Friden B, Lundin $\mathrm{K}$ et al. Cumulative probability of live birth after three in vitro fertilization/intracytoplasmic sperm injection cycles. Ferti Steril 2002; 77: 505-10

4. Pinborg A, Hougaard CO, Nyboe Andersen A et al. Prospective longitudinal cohort study on cumulative 5-year delivery and adoption rates among 1338 couples initiating infertility treatment. Hum Reprod 2009: 24: 991 -9.

5. Witsenburg C, Dieben S, Van der Westerlaken L et al. Cumulative live birth rates in cohorts of patients treated with in vitro fertilization or intracytoplasmic sperm injection. Fertil Steril 2005; 84: 99-107.

6. Kahn JA, von Düring V, Sunde A et al. The efficacy and efficiency of an in-vitro fertilization programme including embryo cryopreservation: a cohort study. Hum Reprod 1993; 8: 247-52.

7. Kahn JA, Sunde A, von Düring $V$ et al. Treatment of unexplained infertility. Fallopian tube sperm perfusion (FSP). Acta Obstet Gynecol Scand 1993. 72: 193-9

8. Tanbo T, Kjekshus E, Dale PO et al. Intracytoplasmatisk spermieinjeksjon. Tidsskr Nor Laegeforen 1998; 118: 864-9.

9. Hanevik HI, Friberg UM, Bergh A et al. Spermieuthenting fra testikkel for assistert befruktning ved azoospermi. Tidsskr Nor Lægeforen 2007; 127 2504-6.

10. Forskrift om innsamling og behandling av helseopplysninger i Medisinsk fødselsregister (Medisinsk fødselsregisterforskriften). FOR 2001-12-21 nr 1483. www.lovdata.no/for/sf/ho/ xo-20011221-1483.html.

11. Stewart LM, Holman CD, Hart R et al. How effective is in vitro fertilization, and how can it be improved? Fertil Steril 2011; 95: 1677-83.

12. Sharma V, Allgar V, Rajkhowa M. Factors influencing the cumulative conception rate and discontinuation of in vitro fertilization treatment for infertility. Fertil Steril 2002; 78: 40-6.

13. Romundstad LB, Romundstad PR, Sunde A et al. Effects of technology or maternal factors on perinatal outcome after assisted fertilisation: a population-based cohort study. Lancet 2008; 372: 737-43.

14. Olivius C, Friden B, Borg G et al. Why do couples discontinue in vitro fertilization treatment? A cohort study. Fertil Steril 2004: 81: 258-61.

15. Grant J, Hoorens S, Gallo F et al. Should ART be part of a population policy mix? A preliminary assessment of the demographic and economic impact of Assisted Reproductive Technologies. Cambridge: RAND Europe, 2006.

Mottatt 30.8.2011, første revisjon innsendt 22.12. 2011, godkjent 19.1. 2012. Medisinsk redaktør Are Brean. 